\title{
Uterine tumors resembling ovarian sex cord tumors are polyphenotypic neoplasms with true sex cord differentiation
}

\author{
Julie A Irving ${ }^{1}$, Silvestro Carinelli ${ }^{2}$ and Jaime Prat $^{3}$ \\ ${ }^{1}$ Department of Pathology, Vancouver General Hospital, Vancouver, Canada; ${ }^{2}$ Department of Pathology, \\ Ospedale Policlinico, Mangiagalli e Regina Elena, Milano, Italy and ${ }^{3}$ Department of Pathology, Hospital de la \\ Santa Creu i Sant Pau, Autonomous University of Barcelona, Spain
}

\begin{abstract}
In this study, we present the clinicopathologic features and immunophenotypic characteristics of five cases of uterine tumors resembling ovarian sex cord tumors and three cases of endometrial stromal tumors with sex cord-like elements, with emphasis on immunohistochemical markers of sex cord differentiation. The mean patient age was 42 years (range 19-69 years), and vaginal bleeding was the most common clinical presentation. The tumors were usually polypoid masses arising in the uterine fundus, with a mean tumor size of $6.7 \mathrm{~cm}$. Sex cord patterns in uterine tumors resembling ovarian sex cord tumors, including anastomosing cords, trabeculae, small nests, tubules, and in one case, a striking retiform architecture with Leydig-like cells, comprised from 70 to $100 \%$ of the tumor volume. All uterine tumors resembling ovarian sex cord tumors were positive for two or more markers of sex cord differentiation; all five cases showed strong immunoreactivity for calretinin, with coexpression of CD99 (four cases), Melan-A (two cases), and inhibin (two cases). Endometrial stromal tumors with sex cord-like elements were less frequently positive for markers of sex cord differentiation, with each case positive for one marker (calretinin, two cases; CD99, one case). In addition, all eight cases were frequently positive for cytokeratin, CD10, vimentin, estrogen receptor, and progesterone receptor; desmin immunoreactivity, when present, was limited to minor foci of smooth muscle. Overall, the morphologic and immunohistochemical findings in uterine tumors resembling ovarian sex cord tumors strongly support that these unusual uterine tumors are polyphenotypic neoplasms with true sex cord differentiation. Modern Pathology (2006) 19, 17-24. doi:10.1038/modpathol.3800475; published online 5 August 2005
\end{abstract}

Keywords: uterine tumors resembling ovarian sex cord tumors; UTROSCT; calretinin; melan-A; CD99; inhibin

Uterine tumors resembling ovarian sex cord tumors (UTROSCT) are an unusual group of stromal neoplasms exhibiting prominent sex cord-like differentiation. In their initial description almost 30 years ago, UTROSCT were designated as Group II tumors, characterized by benign behavior, to distinguish them from endometrial stromal tumors with sex cord-like elements (ESTSCLE; Group I tumors) which were associated with increased risk of recurrence and metastasis. ${ }^{1}$ UTROSCT are placed

Correspondence: Dr J Prat, MD, FRCPath, Department of Pathology, Hospital de la Santa Creu i Sant Pau, Sant Antoni M. Claret, 167, Barcelona 08025, Spain.

E-mail: jprat@hsp.santpau.es

Financial support: Dr Irving is the recipient of the Postgraduate Scholarship in Medicine (Becas-MAE) awarded by the Agencia Española de Cooperación Internacional, Madrid, Spain and of the Eli Lilly Fellowship awarded by the British Columbia Cancer Agency, Vancouver, Canada.

Received 25 May 2005; revised and accepted 7 July 2005; published online 5 August 2005 in the miscellaneous category in the most recent World Health Organization classification of tumors of the uterine corpus, ${ }^{2}$ although most investigators consider these rare neoplasms to be variants of endometrial stromal tumors. ${ }^{3}$

UTROSCT show a predominant, if not exclusive, pattern of cords, nests, and trabeculae resembling granulosa or Sertoli cell tumors of the ovary, while ESTSCLE contain focal sex cord-like areas in a background of an otherwise typical endometrial stromal nodule or endometrial stromal sarcoma. True Leydig cell differentiation has not been described in these tumors, although some cases have been observed to contain luteinized-like cells with abundant eosinophilic or foamy cytoplasm. ${ }^{4-7}$ Numerous immunohistochemical and ultrastructural studies have attempted to phenotype the sex cord-like cells in UTROSCT and ESTSCLE, with variable evidence supporting myoid, ${ }^{8-14}$ epithelial, ${ }^{4,15}$ and true sex cord differentiation. , $^{6,16-20}$ Specifically, inhibin and CD99,,$^{3,6,7,14,17-21}$ as well as 
Melan-A, ${ }^{19,21}$ and most recently, calretinin, ${ }^{7,20}$ have been utilized as immunohistochemical markers of sex cord differentiation in UTROSCT and ESTSCLE based on application of these markers to sex cordstromal tumors of the ovary. ${ }^{22-29}$

The present study was initiated following the diagnosis of a UTROSCT exhibiting a striking retiform pattern and Leydig-like stromal cells, indistinguishable from a Sertoli-Leydig cell tumor of the ovary. This index case prompted an immunohistochemical and clinicopathologic study of UTROSCT and ESTSCLE, with emphasis on the more recently used markers of sex cord differentiation. We sought to determine the diagnostic utility of these and other markers and to contribute to the understanding of the phenotype and behavior of these unusual tumors.

\section{Materials and methods}

Five UTROSCT and three ESTSCLE were retrieved from the consultation files of one of the authors (JP). Clinical information, including presenting symptom, surgery, adjuvant therapy, and patient outcome was obtained from the contributing pathologists and gynecologists. All available pathology reports were examined and the diagnosis confirmed in each case by review of hematoxylin- and eosin-stained slides. Tumors were evaluated for approximate proportions of sex cord, endometrial stromal, and smooth muscle elements; tumors with predominant $(>50 \%)$ or minor $(\leq 50 \%)$ sex cord differentiation were diagnosed as UTROSCT and ESTSCLE, respectively. Other histologic parameters including infiltrative margins, vascular invasion, nuclear atypia, mitotic index, and necrosis were also assessed.

Immunohistochemistry was performed on all eight cases for calretinin, melan A, CD99, inhibin, CD10, desmin, cytokeratin (CAM 5.2), vimentin, estrogen receptor, and progesterone receptor. Sources and dilutions of these antibodies are provided in Table 1. Heat-induced antigen retrieval was conducted by immersion of the sections in sodium citrate buffer $(0.01 \mathrm{M}$ sodium-citrate mono- hydrate, $\mathrm{pH}$ 6.0) or EDTA buffer ( $\mathrm{pH}$ 8.0) and incubation in an autoclave (Matachana, Barcelona, Spain) at $120^{\circ} \mathrm{C}$ for $10 \mathrm{~min}$. The immunohistochemical reactions were performed in a Dako TechMate Horizon immunostainer and visualized following the EnVision system with diaminobenzidine as the chromogen. Immunohistochemical staining was graded as 0 (negative), $1+(<10 \%$ positive cells), $2+(10-50 \%$ positive cells), or $3+(>50 \%$ positive cells). Positive tissue control and negative control slides, the latter performed by omission of the primary antibody, were included with each batch of immunohistochemical slides.

\section{Results}

The clinicopathologic features for all eight cases are presented in Tables 2 and 3 . The mean patient age was 42 years (range 19-69 years); the most common clinical presentation was vaginal bleeding (data not shown). Patients underwent total abdominal hysterectomy and bilateral salpingo-oophorectomy (four cases) or simple hysterectomy (four cases). Evidence of extrauterine spread was present in one patient with ESTSCLE.

Most tumors were polypoid or nodular masses, usually located in the uterine fundus, with a mean tumor size of $6.7 \mathrm{~cm}$ (range $3.5-14 \mathrm{~cm}$ ). Infiltrative margins were noted in two UTROSCT and in two ESTSCLE. Microscopically, two UTROSCT consisted exclusively of sex cord elements; one of these, the index case (case 1), exhibited a striking retiform pattern, with many small papillae showing hyalinized cores lined by cuboidal cells (Figure 1a). Discrete nodules of polygonal, Leydig-like cells with abundant eosinophilic cytoplasm and round nuclei were scattered throughout the tumor (Figure 1b). Crystals of Reinke were not identified. In the remaining cases, sex cord patterns in both UTROSCT and ESTSCLE were variable but most commonly consisted of thin anastomosing cords, trabeculae, small nests, and tubules (Figure 2a and b). Cells typically had scant cytoplasm and round to oval nuclei with indistinct nucleoli.

Table 1 Sources and dilutions of antibodies

\begin{tabular}{lll}
\hline Antibody & Dilution & Source \\
\hline Calretinin & $1: 300 \mathrm{P}$ & Chemicon, San Jose, CA, USA \\
Melan A (A103) & $1: 50 \mathrm{M}$ & Dako, CA, USA \\
CD99 & $1: 100 \mathrm{M}$ & Signet, Dedham, MA, USA \\
Inhibin & $1: 2 \mathrm{M}$ & Serotec, Oxford, UK \\
CD10 & $1: 40 \mathrm{M}$ & Novocastra, Newcastle, UK \\
Desmin & $1: 100 \mathrm{M}$ & Dako, CA, USA \\
CAM 5.2 & $1: 5 \mathrm{M}$ & Becton Dickinson, San Jose, CA, USA \\
Vimentin & $1: 300 \mathrm{M}$ & Dako, CA, USA \\
Estrogen receptor & $1: 40 \mathrm{M}$ & Novocastra, Newcastle, UK \\
Progesterone receptor & $1: 300 \mathrm{M}$ & Novocastra, Newcastle, UK
\end{tabular}

P, polyclonal; M, monoclonal. 
Table 2 Clinical summary of UTROSCT (cases 1-5) and ESTSCLE (cases 6-8)

\begin{tabular}{|c|c|c|c|c|c|}
\hline Case & Age & Surgery & $\begin{array}{l}\text { Extrauterine } \\
\text { spread }\end{array}$ & Adjuvant treatment & Patient outcome \\
\hline 1 & 45 & TAH-BSO & No & None & NED 1 year 10 months \\
\hline 2 & 26 & $\mathrm{SH}$ & No & None & NED 3 years \\
\hline 3 & 43 & $\mathrm{SH}$ & No & Not known & Lost to follow-up \\
\hline 4 & 28 & Myomectomy, subsequent SH & No & None & NED 5 years 2 months \\
\hline 5 & 69 & TAH-BSO & No & $\begin{array}{l}\text { Radiotherapy to pelvis, vaginal vault } \\
\text { brachytherapy }\end{array}$ & NED 3 years 11 months \\
\hline 6 & 19 & $\mathrm{SH}$ & No & None & NED 2 years \\
\hline 7 & 55 & TAH-BSO & Yes & Chemotherapy & DOD 10 months \\
\hline 8 & 48 & TAH-BSO & No & None & NED 1 year 3 months \\
\hline
\end{tabular}

LN, lymph node; DOD, died of disease; NED, no evidence of disease; SH, simple hysterectomy; TAH-BSO, total abdominal hysterectomy and bilateral salpingo-oophorectomy.

Table 3 Gross and microscopic features for UTROSCT (cases 1-5) and ESTSCLE (cases 5-8)

\begin{tabular}{|c|c|c|c|c|c|c|c|}
\hline Case & $\begin{array}{l}\text { Tumor } \\
\text { size }(\mathrm{cm})\end{array}$ & Gross description & $\begin{array}{l}\text { Infiltrative } \\
\text { margins }\end{array}$ & Nuclear atypia & $\begin{array}{l}\text { Mitoses/ } \\
10 \mathrm{HPF}\end{array}$ & Necrosis & $\begin{array}{l}\text { Vascular } \\
\text { invasion }\end{array}$ \\
\hline 1 & 8.5 & $\begin{array}{l}\text { Polypoid intrauterine mass protruding } \\
\text { through cervical os }\end{array}$ & Yes & Moderate & 1 & No & Yes \\
\hline 2 & 5 & Polypoid intrauterine mass & Yes & Mild-to-moderate & 3 & No & No \\
\hline 3 & 5 & NA & UTA & Mild-to-moderate & 2 & No & No \\
\hline 4 & 5 & Intramural, solid mass & UTA & Mild & 1 & No & No \\
\hline 5 & 7 & Nodular mass filling uterine cavity & No & Mild & 3 & No & No \\
\hline 6 & 3.5 & Nodule in fundus & Yes & Moderate & 5 & No & Yes \\
\hline 7 & 14 & $\begin{array}{l}\text { Nodular mass in fundus, solid, whitish, } \\
\text { firm, with gelatinous areas }\end{array}$ & Yes & Moderate & 6 & Yes & Yes \\
\hline 8 & 5.5 & $\begin{array}{l}\text { Nodular mass in fundus, irregular } \\
\text { margins, whitish, firm }\end{array}$ & Yes & Mild & 1 & No & Yes \\
\hline
\end{tabular}

NA, not available; UTA, unable to assess due to tumor fragmentation.

Five tumors (3/5 UTROSCT and 2/3 ESTSCLE) contained a mature smooth muscle component, in four cases consisting of occasional small nodules and fascicles of cells interspersed between the sex cord areas (Figure 2a). One ESTSCLE (case 7) showed focal areas with a starburst pattern of cells surrounding a central hyalinized core. One UTROSCT contained scattered foam cells, consisting of single cells and small aggregates of cells with round, central nuclei and abundant clear to foamy cytoplasm (Figure 2c). Minor foci of endometrial stromal-type cells were evident in one UTROSCT, arranged in ill-defined, cellular clusters merging with the adjacent sex cord areas. The stromal cells had minimal cytoplasm, with small, oval nuclei and even chromatin.

Nuclear atypia was mild to moderate in all eight cases. The mitotic index was low in the UTROSCT group, ranging from one to three mitoses per 10 high-power fields, and up to six mitoses per 10 high-power fields in the ESTSCLE group. Necrosis was present only in the largest tumor of the series (case 7). Vascular invasion was present in all three ESTSCLE but in only one UTROSCT. Of the three ESTSCLE, two tumors demonstrated usual low-grade endometrial stromal sarcoma; one case consisted of high-grade stromal sarcoma (case 7).

The immunohistochemical profile of each case and their relative proportions of sex cord, endometrial stromal, and smooth muscle elements are given in Table 4. Each of the five UTROSCT cases were immunoreactive for two or more markers of sex cord differentiation. All five UTROSCT were strongly immunoreactive for calretinin, with coexpression of CD99 in four cases, melan-A in two cases, and inhibin in two cases. The index UTROSCT case showed immunoreactivity for calretinin (Figure 1c) and melan-A (Figure 1d) in both the Sertoli- and Leydig-like components, while only the latter was positive for inhibin. Three of the remaining UTROSCT cases and all three ESTSCLE were inhibin negative. In case 4 , the sex cord cell and foam cell components showed immunoreactivity for calretinin, CD99, and inhibin (Figures 2d-f). Immunohistochemical staining for calretinin was present in two of three ESTSCLE but with less intensity than that observed in the UTROSCT group. All three ESTSCLE were negative for Melan A; one case was immunoreactive for CD99.

CD10 was variably positive in 4/5 UTROSCT and strongly positive in $2 / 3$ ESTSCLE. Of the five cases 

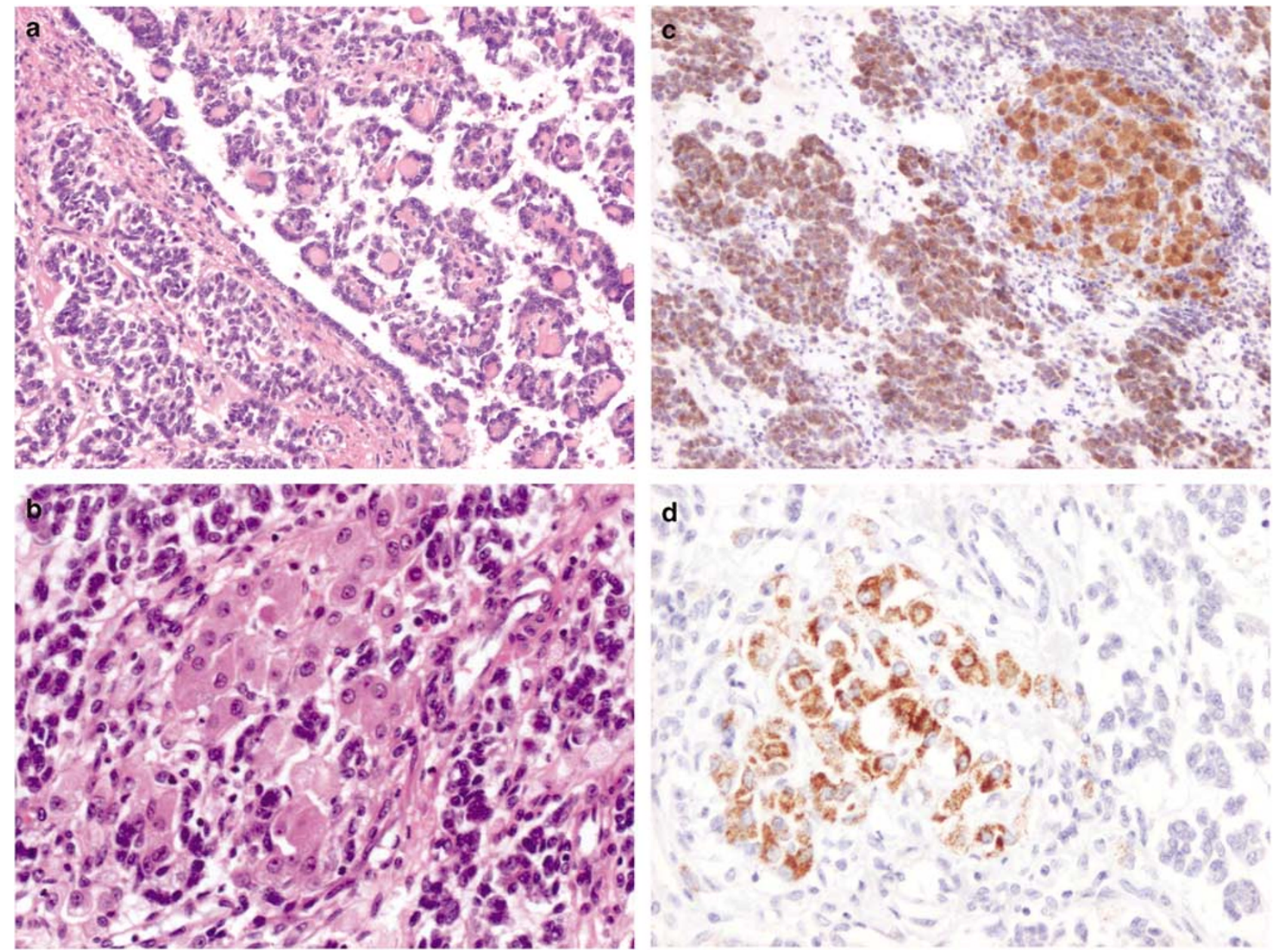

Figure 1 UTROSCT (Case 1) with a striking retiform pattern composed of small papillae with hyalinized cores projecting into larger cyst (a) and clusters of Leydig-like cells (b). Irregularly branching, slit-like tubules were seen elsewhere. The tumor cells were strongly positive for calretinin (c). Melan-A immunoreactivity in Leydig-like cells is shown in (d).

with desmin immunoreactivity, four showed positive staining only in the smooth muscle component. All eight cases were strongly immunoreactive for vimentin, and the majority (6/8 cases) were cytokeratin positive. Three UTROSCT showed ER immunoreactivity, in two cases restricted to the sex cord elements, while four UTROSCT were PR positive. Two ESTSCLE were positive for both ER and PR.

Information regarding adjuvant therapy and clinical follow-up was available for seven patients (Table 2). For four patients with UTROSCT, three received no additional treatment and one underwent pelvic radiotherapy with brachytherapy to the vaginal vault; all four patients were alive without evidence of disease at a mean of 3.5 years. The fourth patient (case 3) had no residual tumor in the hysterectomy specimen and was subsequently lost to follow-up. Of the three patients with ESTSCLE, two received no additional therapy and are without evidence of disease at 1 year 3 months and 2 years. The third patient (case 7) received chemotherapy but developed pulmonary and bony metastases and died of disease 10 months from the operative date.

\section{Discussion}

Since the initial description of UTRSOCT in 1976, there have been numerous efforts to further characterize this unusual group of uterine neoplasms. Results have been variable, with ultrastructural and immunohistochemical evidence of myogenic, epithelial, and sex cord differentiation. ${ }^{6-20}$ In the present study, we applied a panel of antibodies, inclusive of the most recently identified markers of sex cord differentiation (calretinin, melan A, CD99, and inhibin) as well as smooth muscle and endometrial stroma, to a series of UTROSCT and ESTSCLE. We found that all UTROSCT were immunoreactive for at least two markers of sex cord differentiation, often with coexpression of cytokeratin, CD10, vimentin, estrogen receptor, and progesterone receptor; desmin immunoreactivity, when 

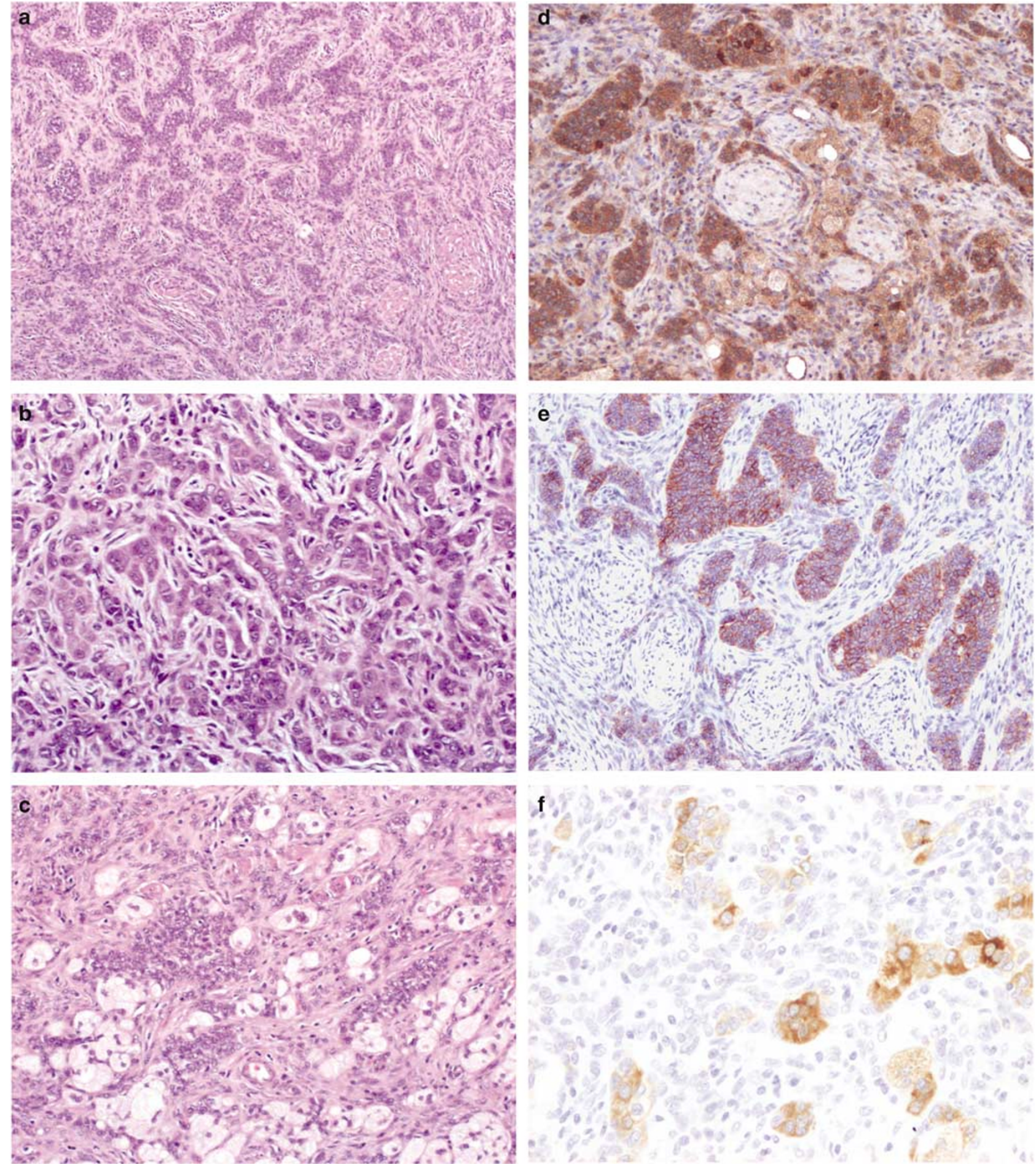

Figure 2 UTROSCT (Case 4) with anastomosing cords and nests of cells (a, b) and occasional small nodules of smooth muscle (a). Foci of scattered foam cells were present (c). The tumor cells showed strong immunoreactivity for calretinin (d) and CD99 (e); less than $10 \%$ of cells were inhibin positive (f).

present, was restricted to minor foci of smooth muscle. Our results support that UTROSCT are polyphenotypic neoplasms with true sex cord differentiation. As shown in Table 5, our data are in general agreement with previous studies addressing the issue of immunohistochemical expression of sex cord markers in UTROSCT ${ }^{6,7,14,17-21,24,30}$ and is the first to concurrently examine the four most commonly used markers. This literature review also highlights that ESTSCLE, or Type I tumors, less frequently show immunoreactivity for markers of sex cord differentiation, a finding which correlates 
Table 4 Summary table of immunohistochemical results for UTROSCT (cases 1-5) and ESTSCLE (cases 6-8)

\begin{tabular}{|c|c|c|c|c|c|c|c|c|c|c|c|c|c|}
\hline \multirow[t]{2}{*}{ Case } & \multicolumn{3}{|c|}{$\%$} & \multirow[t]{2}{*}{ Cal-retinin } & \multirow[t]{2}{*}{ CD99 } & \multirow[t]{2}{*}{ Melan- $A$} & \multirow[t]{2}{*}{ Inhibin } & \multirow[t]{2}{*}{ CD10 } & \multirow[t]{2}{*}{ Desmin } & \multirow[t]{2}{*}{ CAM 5.2} & \multirow[t]{2}{*}{ Vimentin } & \multirow[t]{2}{*}{$E R$} & \multirow[t]{2}{*}{$P R$} \\
\hline & $S C$ & $E S$ & $S M$ & & & & & & & & & & \\
\hline 1 & 100 & 0 & 0 & +++ & - & ++ & $t^{\mathrm{a}}$ & +++ & - & ++ & +++ & - & ++ \\
\hline 2 & 100 & 0 & 0 & +++ & + & - & - & ++ & - & - & +++ & - & - \\
\hline 3 & 90 & 0 & 10 & $+++^{\mathrm{b}}$ & $+^{\mathrm{b}}$ & $t^{\mathrm{b}}$ & - & + & $+^{\mathrm{c}}$ & $+++^{\mathrm{b}}$ & +++ & $+++^{\mathrm{b}}$ & +++ \\
\hline 4 & 80 & 0 & 20 & $+++{ }^{\mathrm{d}}$ & $+++{ }^{\mathrm{d}}$ & - & $+^{\mathrm{d}}$ & $+^{\mathrm{d}}$ & $t^{\mathrm{c}}$ & ++ & $+++^{\mathrm{d}}$ & + & $+++^{\mathrm{d}}$ \\
\hline 5 & 70 & 10 & 20 & +++ & + & - & - & - & $+^{\mathrm{C}}$ & $+++^{\mathrm{b}}$ & +++ & $++^{\mathrm{b}}$ & +++ \\
\hline 6 & 40 & 60 & 0 & ++ & - & - & - & +++ & - & +++ & +++ & +++ & +++ \\
\hline 7 & 10 & 80 & 10 & - & ++ & - & - & - & $++^{\mathrm{c}}$ & ++ & ++ & - & - \\
\hline 8 & 5 & 50 & 45 & + & - & - & - & +++ & ++ & - & +++ & + & + \\
\hline
\end{tabular}

ES, endometrial stromal; SC, sex cord; SM, smooth muscle.

${ }^{\mathrm{a}}$ Leydig-like cells only.

${ }^{\mathrm{b}}$ Sex cord cells only.

${ }^{\mathrm{c}}$ Smooth muscle cells only.

${ }^{\mathrm{d}}$ Foam cells and sex cord elements.

- , negative, $+,<10 \%,++, 10-50 \%,+++,>50 \%$.

Table 5 Summary table of immunohistochemical staining of ESTSCLE (I) and UTROSCT (II) for markers of sex cord differentiation

\begin{tabular}{|c|c|c|c|c|c|c|c|c|}
\hline \multirow{2}{*}{ Reference } & \multicolumn{2}{|c|}{ Calretinin } & \multicolumn{2}{|c|}{ CD99 } & \multicolumn{2}{|c|}{ Melan- $A$} & \multicolumn{2}{|c|}{ Inhibin } \\
\hline & $I$ & $I I$ & $I$ & $I I$ & $I$ & $I I$ & $I$ & $I I$ \\
\hline $\mathrm{LoO}^{24}$ & - & - & - & $1 / 1$ & - & - & - & - \\
\hline Krishnamurthy $^{17}$ & - & - & - & $7 / 7$ & - & $4 / 7$ & - & $3 / 7$ \\
\hline Baker $^{6}$ & - & - & $2 / 10$ & $5 / 5$ & - & - & $2 / 10$ & $5 / 5$ \\
\hline McCluggage $^{18}$ & - & - & $1 / 2$ & - & - & - & $1 / 2$ & - \\
\hline Hauptmann ${ }^{19}$ & - & - & - & $1 / 1$ & - & $0 / 1$ & - & $0 / 1$ \\
\hline Suzuki $^{21}$ & - & - & - & $1 / 1$ & - & $0 / 1$ & - & $0 / 1$ \\
\hline Oliva $^{30}$ & - & - & - & $4 / 7$ & - & - & - & $1 / 7$ \\
\hline Nogales $^{7}$ & - & $1 / 1$ & - & $1 / 1$ & - & - & - & $1 / 1$ \\
\hline Kabbani $^{20}$ & - & $1 / 1$ & - & - & - & - & - & $0 / 1$ \\
\hline Ohta $^{14}$ & - & - & $0 / 1$ & - & - & - & - & - \\
\hline Current & $2 / 3$ & $5 / 5$ & $1 / 3$ & $4 / 5$ & $0 / 3$ & $2 / 5$ & $0 / 3$ & $2 / 5$ \\
\hline Total & $2 / 3(67 \%)$ & $7 / 7(100 \%)$ & $4 / 16(25 \%)$ & $24 / 28(86 \%)$ & $0 / 3(0 \%)$ & $6 / 14(43 \%)$ & $3 / 16(19 \%)$ & $12 / 28(43 \%)$ \\
\hline
\end{tabular}

with their morphologic appearance and relatively minor component of sex cord elements. ${ }^{6,14,18}$

Of the five UTROSCT analyzed in this study, the proportion of sex cord elements comprised between 70 and $100 \%$ of the tumor volume, based on routine microscopic evaluation. In most cases, the sex cord formations consisted of thin cords, trabeculae, and nests of cells; in the index case, a striking retiform pattern with interspersed clusters of eosinophilic Leydig-like cells was present, indistinguishable from an ovarian Sertoli-Leydig cell tumor. Eosinophilic cells resembling luteinized stromal cells have been described, ${ }^{6,7}$ as well as foam cells, ${ }^{1,4,6,7}$ both of which have shown strong inhibin and CD99 immunoreactivity. ${ }^{6,7}$ In our index UTROSCT case, composed exclusively of sex cord elements, inhibin immunoreactivity was restricted to the Leydig-like cell component, while calretinin and Melan-A were diffusely positive. The morphology and immuno- phenotype of foam cells, eosinophilic 'luteinized' cells, and Leydig-like cells suggests that they represent a spectrum of variably differentiated sex cord cells. Indeed, some authors have suggested that these cells may have steroid-producing function, although this remains speculative at present. ${ }^{7}$

Overall, calretinin was the most consistently expressed sex cord marker, present in $>50 \%$ of cells in all five UTROSCT and in two of three ESTSCLE $(<10$ and $10-50 \%$ of tumor cells positive). To the best of our knowledge, description of calretinin immunoreactivity in UTROSCT is limited to two previous case reports, both of which have also been positive (Table 2), ${ }^{7,20}$ this is the first report of calretinin immunostaining in ESTSCLE. Calretinin, a calcium-binding protein, is expressed by theca interna cells, hilus cells, a minor proportion of individual stromal cells, and surface epithelium of the normal ovary, ${ }^{27}$ and has recently emerged as a 
marker of sex cord-stromal tumors of the ovary. The vast majority of granulosa cell tumors, SertoliLeydig cell tumors, and fibroma-thecomas of the ovary have been positive for calretinin; ${ }^{26,28,29}$ only occasional granulosa cell tumors and fibrothecomas have been calretinin negative. ${ }^{27}$ Studies have shown that calretinin may be a more sensitive marker than inhibin in this setting, and be of particular use in ovarian sex cord-stromal tumors that are inhibin negative. ${ }^{28}$ However, calretinin is less specific than inhibin, with one study reporting positivity in approximately one-quarter of ovarian surface epithelial carcinomas tested, compared with only $2 \%$ showing inhibin positivity. ${ }^{28}$

CD99 is the MIC2 gene product initially heralded as a marker for Ewing's sarcoma and peripheral neuroectodermal tumor, which, similar to calretinin, stains sex cord-stromal tumors of the ovary and testis as well as their normal cell counterparts. ${ }^{24,31-33}$ Membranous CD99 immunostaining can be positive in other mesenchymal uterine neoplasms including leiomyoma variants and endometrial stromal tumors, lessening its utility as a differential diagnostic marker in this setting. ${ }^{30}$ However, it is noteworthy that 24 of 28 UTROSCT (86\%) have been CD99positive (Table 5)..$^{6,7,17,19,21,24,30}$

Studies of Melan-A expression in UTROSCT are limited. Two of five UTROSCT in the present study were focally Melan-A positive, similar to Krishnamurthy et $a l^{17}$ who found four of seven UTROSCT positive for Melan-A in $<10$ to $10-50 \%$ of tumor cells. As Melan-A stains steroid-producing cells in the ovary, testis, and adrenal cortex, ${ }^{34}$ it has been suggested that Melan-A immunoreactivity in UTROSCT supports a specialized gonadal stromal phenotype. ${ }^{17}$

A component of smooth muscle can be seen in UTROSCT, recognizable on routine staining as small bundles and nodules of cells very similar to normal myometrium. ${ }^{3}$ In our experience, these foci are highlighted by desmin immunostaining. Although a diffuse pattern of desmin immunoreactivity in UTROSCT has been reported,, ${ }^{3,30}$ this finding warrants strong consideration of a smooth muscle neoplasm, including epithelioid variants; h-caldesmon is usually negative in UTROSCT and positive in uterine smooth muscle tumors, and is a more useful marker in this distinction. ${ }^{30}$ It is unclear whether the bundles of smooth muscle in UTROSCT represent entrapped normal tissue or a divergent line of differentiation. ${ }^{3}$

Our morphologic and immunohistochemical findings indicate that UTROSCT arise from pluripotent mesenchymal cells, which predominantly differentiate into sex cord cells. Evidence supports that focal smooth muscle and endometrial stromal cell differentiation can also occur. Accordingly, we recommend the use of an immunohistochemical panel to facilitate the diagnosis of UTROSCT, including two markers of sex cord differentiation (calretinin and one of either melan A, CD99, or inhibin), desmin, cytokeratin, and CD10. This panel should discriminate between UTROSCT and smooth muscle neoplasms, as the latter should be negative for sex cord markers, cytokeratin, and usually CD10, but diffusely positive for desmin. Distinction of UTROSCT from endometrial stromal tumors can be subjective, but we agree with that UTROSCT is a designation that should be reserved for tumors with predominant $(>50 \%)$ or exclusive sex cord differentiation.

The long-term clinical behavior of UTROSCT remains to be established. Although favorable histologic features including well-circumscribed borders and an absence of vascular invasion are usually present, these tumors may on occasion show infiltrative borders and focal vascular invasion, albeit not to the extent that is characteristic of endometrial stromal sarcomas. Four of our cases with follow-up, including two cases with either or both infiltrative margins and focal vascular invasion, have had favorable outcomes. However, as the duration of follow-up is still limited, we and others advocate consideration of these neoplasms as having an uncertain but probably low likelihood of recurrence, with acknowledgement that no extrauterine spread or distant metastasis have been reported. ${ }^{1,3}$

\section{Acknowledgements}

This work was presented in part at the US and Canadian Academy of Pathology Meeting, March 2005, San Antonio, TX, USA. We thank the following individuals for their contribution of cases: $\mathrm{Dr}$ Mario Arguelles (Gijon, Spain), Dr Giovanni Negri (Bolzano, Italy), Dr Isidora Serrano (Aranda de Duero, Spain), Dr Teresa Simoes de Silva (Coimbra, Portugal), Dr Pietro Muretto (Pesaro, Italy), Dr Concha Muñoz (Barcelona, Spain), Dr Lluis Colomo (Barcelona, Spain).

\section{References}

1 Clement PB, Scully RE. Uterine tumors resembling ovarian sex-cord tumor. A clinicopathologic analysis of fourteen cases. Am J Clin Pathol 1976;66:512-525.

2 Silverberg SG, Kurman RJ, Nogales F, et al. Tumours of the uterine corpus. In: Tavassoli FA, Devilee P (eds). Pathology and Genetics of Tumours of the Breast and Female Genital Organs. IARC Press: Lyon, France, 2003, pp 217-257.

3 Oliva E, Clement PB, Young RH. Endometrial stromal tumors: an update on a group of tumors with a protean phenotype. Adv Anat Pathol 2000;5:257-281.

4 Fekete PS, Vellios F, Patterson BD. Uterine tumor resembling ovarian sex-cord tumor: report of a case of an endometrial stromal tumor with foam cells and ultrastructural evidence of epithelial differentiation. Int J Gynecol Pathol 1985;4:378-387. 
5 Suarez-Vilela D, Izquierdo-Garcia FM. Foam cells and histiocytes in endometrial stromal tumours. Histopathology 1998;32:568-569.

6 Baker RJ, Hildebrandt RH, Rouse RV, et al. Inhibin and CD99 (MIC2) expression in uterine stromal neoplasms with sex-cord-like elements. Hum Pathol 1999;30: 671-679.

7 Nogales FF, Isaac MA. Functioning uterine sex cord tumour. Histopathology 2002;41:277-279.

8 Tang CK, Toker C, Ances IG. Stromomyoma of the uterus. Cancer 1979;43:308-316.

9 Lillemoe TJ, Perrone T, Norris HJ, et al. Myogenous phenotype of epithelial-like areas in endometrial stromal sarcomas. Arch Pathol Lab Med 1991;115: 215-219.

10 McCluggage WG, Shah V, Walsh MY, et al. Uterine tumor resembling ovarian sex cord tumour: evidence for smooth muscle differentiation. Histopathology 1993;23:83-85.

11 McCluggage WG, Date A, Bharucha H, et al. Endometrial stromal sarcoma with sex cord-like areas and focal rhabdoid differentiation. Histopathology 1996;29: 369-374.

12 Fukunaga M, Miyazawa Y, Ushigome S. Endometrial low-grade stromal sarcoma with ovarian sex cord like differentiation: report of two cases with an immunohistochemical and flow cytometric study. Pathol Int 1997;47:412-415.

13 Zamecnik M, Michal M. Endometrial stromal nodule with retiform sex-cord-like differentiation. Pathol Res Pract 1998;194:449-453.

14 Ohta Y, Suzuki T, Kojima M, et al. Low-grade endometrial stromal sarcoma with an extensive epithelial-like element. Pathol Int 2003;53:246-251.

15 Mazur MT, Kraus FT. Histogenesis of morphologic variations in tumors of the uterine wall. Am J Surg Pathol 1980;4:59-74.

16 Kantelip B, Cloup N, Dechelotte P. Uterine tumor resembling ovarian sex cord tumors: report of a case of an endometrial stromal tumor with ultrastructural study. Hum Pathol 1986;17:91-94.

17 Krishnamurthy S, Jungbluth AA, Busam KJ, et al. Uterine tumors resembling ovarian sex-cord tumors have an immunophenotype consistent with true sex-cord differentiation. Am J Surg Pathol 1998; 22:1078-1082.

18 McCluggage WG. Uterine tumors resembling ovarian sex cord tumours: immunohistochemical evidence for true sex cord differentiation. Histopathology 1999;34:375-376.

19 Hauptmann S, Nadjari B, Kraus J, et al. Uterine tumor resembling ovarian sex-cord tumor-a case report and review of the literature. Virchows Arch 2001;439: 97-101.

20 Kabbani W, Deavers MT, Malpica A, et al. Uterine tumor resembling ovarian sex-cord tumor: report of a case mimicking cervical adenocarcinoma. Int J Gynecol Pathol 2003;22:297-302.
21 Suzuki C, Matsumoto T, Fukunaga M, et al. Uterine tumors resembling ovarian sex-cord tumors producing parathyroid hormone-related protein of the uterine cervix. Pathol Int 2002;52:164-168.

22 Rishi M, Howard LN, Bratthauer GL, et al. Use of monoclonal antibody against human inhibin as a marker for sex cord-stromal tumors of the ovary. Am J Surg Pathol 1997;21:583-589.

23 Matias-Guiu X, Prat J. Alpha-inhibin immunostaining in diagnostic pathology. Adv Anat Pathol 1998;5: 263-267.

24 Loo KT, Leung AKF, Chan JKC. Immunohistochemical staining of ovarian granulosa cell tumours with a MIC2 antibody. Histopathology 1995;27:388-390.

25 Busam KJ, Iversen K, Coplan KA, et al. Immunoreactivity for A103, an antibody to melanocytic antigen Melan-A (Mart-1) in adrenocortical and other steroid tumors. Am J Surg Pathol 1998;22:57-63.

26 McCluggage WG, Maxwell P. Immunohistochemical staining for calretinin is useful in the diagnosis of ovarian sex cord-stromal tumours. Histopathology 2001;38:403-408.

27 Cao QJ, Jones JG, Li M. Expression of calretinin in human ovary, testis, and ovarian sex cord-stromal tumors. Int J Gynecol Pathol 2001;20:346-352.

28 Movahedi-Lankarani S, Kurman RJ. Calretinin, a more sensitive but less specific marker than $\alpha$-inhibin for ovarian sex cord-stromal neoplasms. An immunohistochemical study of 215 cases. Am J Surg Pathol 2002;26:1477-1483.

29 Deavers MT, Malpica A, Liu J, et al. Ovarian sex cordstromal tumors: an immunohistochemical study including a comparison of calretinin and inhibin. Mod Pathol 2003;16:584-590.

30 Oliva E, Young RH, Amin MB, et al. An immunohistochemical analysis of endometrial stromal and smooth muscle tumors of the uterus. A study of 54 cases emphasizing the importance of using a panel because of overlap in immunoreactivity for individual antibodies. Am J Surg Pathol 2002;26:403-412.

31 Gelin C, Aubrit F, Phalipon A, et al. The E2 antigen, a $32 \mathrm{kd}$ glycoprotein involved in T-cell adhesion processes, is the MIC2 gene product. EMBO J 1989;8: 3253-3259.

32 Gordon MD, Corless C, Renshaw AA, et al. CD99, keratin, and vimentin staining of sex cord-stromal tumors, normal ovary, and testis. Mod Pathol 1998;11: 769-773.

33 Stevenson AJ, Chatten J, Bertoni F, et al. CD99 (p30/ 32MIC2) neuroectodermal/Ewing's sarcoma antigen as an immunohistochemical marker. Review of more than 600 tumors and the literature experience. Appl Immunohistochem Mol Morphol 1994;2:231-240.

34 Busam KJ, Iversen K, Coplan KA, et al. Immunoreactivity for A103, an antibody to melanocytic antigen Melan-A (Mart-1), in adrenocortical and other steroid tumors. Am J Surg Pathol 1998;22:57-63. 